\title{
Development of Intestinal Mucosal Immunity in Fetal Life and the First Postnatal Months
}

\author{
TORLEIV O. ROGNUM, PER S. THRANE, LAURITZ STOLTENBERG, \\ ÅSHILD VEGE, AND PER BRANDTZAEG \\ Institute of Forensic Medicine, Laboratory for Immunohistochemistry and Immunopathology (LIIPAT), Institute \\ of Pathology, University of Oslo, The National Hospital, N-0027 Oslo 1, Norway
}

\begin{abstract}
Nine premature infants who were either stillborn or who died shortly after delivery (gestational age, 24-32 wk), eight full-term infants who died during the first 3 postnatal wk, and four infants who died in the postneonatal period were studied by immunohistochemistry for duodenal expression of secretory component (SC) and epithelial HLA class I and II determinants and for the presence of IgA-, IgM-, and IgG-producing immunocytes. Only small amounts of SC appeared before the 29th gestational wk, but thereafter it increased rapidly; 1 wk after birth, SC showed an adult distribution pattern. Epithelial class I was expressed throughout the period investigated, whereas class II (HLA-DR) determinants were absent on the duodenal villi until 1 wk after birth. HLA-DP and -DQ were not expressed by the epithelium. No IgA immunocytes were seen before 1 wk after birth, whereas a few IgM- and IgG-producing cells were present throughout the period studied. The intense epithelial HLA-DR expression from the 2nd postnatal wk, along with $\mathrm{SC}$ and the appearance of IgA immunocytes, suggests that the intestinal immune system is modulated in response to environmental factors shortly after birth. (Pediatr Res 32: 145149, 1992)
\end{abstract}

\section{Abbreviations}

SC, secretory component

$\mathrm{CD}$, cluster designation

A functioning mucosal immune system is probably important for survival in infancy. The SC-mediated epithelial transport of dimeric IgA and pentameric IgM affords a first line defense protecting against environmental factors (1), and it has previously been claimed that a deficiency of SC may cause sudden death in infancy (2) and chronic diarrheal disease (3).

The HLA molecules mediate interactions between antigenpresenting cells and $\mathrm{T}$ lymphocytes required to generate immune responses (4). Class II molecules (HLA-DR, -DP, and -DQ) function mainly as genetically determined restriction elements for CD4+ T cells, whereas class I molecules (HLA-A, -B, and $-C)$ are restriction elements for CD8+ T cells (1). Little is known about the significance of HLA class I and II expression on intestinal epithelium, but it may be involved in suppressor mechanisms resulting in oral tolerance to food antigens (1).

When studying pathologic conditions in infancy, it is important to know what is normal. Age-matched controls and knowl-

Received October 25, 1991; accepted February 24, 1992.

Correspondence: Torleiv O. Rognum, M.D., Institute of Forensic Medicine, Rikshospitalet 0027 Oslo 1, Norway.

Supported by The Norwegian Research Council for Science and the Humanities, The Norwegian Cancer Society, and The Norwegian SIDS Society.
Table 1. Clinicopathologic information about subjects

\begin{tabular}{|c|c|c|c|}
\hline $\begin{array}{c}\text { Subject } \\
\text { no. }\end{array}$ & $\begin{array}{c}\text { Gestational } \\
\text { age }\end{array}$ & Sex & Cause of death \\
\hline 1 & $24 w k$ & $\mathrm{~F}$ & Cerebral hemorrhage \\
\hline 2 & 24 wk & M & Intrauterine septicemia \\
\hline 3 & 27 wk & $\mathrm{F}$ & Anoxic cerebral damage \\
\hline 4 & 29 wk & M & Respiratory distress syndrome \\
\hline 5 & $29 w k$ & $\mathrm{~F}$ & Cerebral hemorrhage \\
\hline 6 & $31 \mathrm{wk}$ & M & Placental separation \\
\hline 7 & $32 \mathrm{wk}$ & M & Transposition of great vessels \\
\hline 8 & $32 \mathrm{wk}$ & $\mathrm{F}$ & Pulmonary hypoplasia \\
\hline \multirow[t]{2}{*}{9} & 32 wk & $\mathrm{F}$ & Intracerebral hemorrhage \\
\hline & $\begin{array}{l}\text { Postnatal } \\
\text { age }\end{array}$ & & \\
\hline 10 & Stillborn & M & Hydrocephalus \\
\hline 11 & $1 \mathrm{~d}$ & $\mathrm{M}$ & Atelectasis of the lungs \\
\hline 12 & $1 \mathrm{~d}$ & $\mathrm{~F}$ & Anoxic cerebral damage \\
\hline 13 & $1 \mathrm{wk}$ & $\mathrm{F}$ & Anoxic cerebral damage \\
\hline 14 & 1.wk & $\mathrm{F}$ & Respiratory distress syndrome \\
\hline 15 & $2 \mathrm{wk}$ & M & Respiratory distress syndrome \\
\hline 16 & $2 \mathrm{wk}$ & M & Anoxic cerebral damage \\
\hline 17 & 3 wk & $\mathrm{F}$ & Anoxic cerebral damage \\
\hline 18 & $16 \mathrm{wk}$ & $\mathrm{F}$ & Tumor cerebri \\
\hline 19 & $16 \mathrm{wk}$ & M & Pierre Robin syndrome \\
\hline 20 & $20 \mathrm{wk}$ & M & Vitium cordis \\
\hline 21 & 24 wk & $\mathrm{F}$ & Myocarditis \\
\hline
\end{tabular}

edge about the ontogeny of secretory immunity are thus required when embarking on studies of disease-associated alterations of the mucosal immune system of infants. There is little systematic information to this end in the literature. The purpose of the present study was therefore to map developmental features of the intestinal immune system during the fetal and the neonatal period and the first months of infancy.

\section{MATERIALS AND METHODS}

Patients. Nine premature infants (gestational age 24-32 wk) who were either stillborn or who died shortly after delivery (median survival time $26 \mathrm{~h}$, range 0-68 h), eight approximately full-term neonates who died during the first 3 postnatal wk, and four infants who died in the postneonatal period between the 16 th and the 24 th wk were investigated. The premature infants were given i.v. glucose. Eight of them received nothing per os, but one infant received two portions of mother's milk. The fullterm neonates were given i.v. glucose the 1st wk after birth. From the 2nd wk, essential amino acids were added. The four eldest infants received mother's milk per os, and two of them also were given porridge made from rice and corn. Clinicopathologic information about the patients is given in Table 1 .

Tissue specimens. Tissue specimens were obtained from the 
Table 2. Characteristics of MAb applied in study

\begin{tabular}{|c|c|c|c|c|}
\hline Specificity & $\begin{array}{l}\text { Murine } \\
\text { isotype }\end{array}$ & $\begin{array}{l}\text { Working } \\
\text { application }\end{array}$ & Reference & Source \\
\hline HLA-DR & $\operatorname{IgG} 2 \mathrm{a}$ & Purified Ig, 1:20 & Lampson and Levy (8) & Becton Dickinson* \\
\hline HLA-DQ & IgGl & Purified Ig, 1:20 & Chen et al. (9) & Becton Dickinson \\
\hline HLA-DP & $\mathrm{IgG} 1$ & Purified Ig, 1:20 & Watson et al. $(10)$ & Becton Dickinson \\
\hline HLA-A, B, C (class I) & $\operatorname{IgG} 2 a$ & Ascitic fluid, 1:80 & Barnstable et al. (11) & Seralab $†$ \\
\hline $\mathrm{CD} 3$ & IgG & Purified Ig, 1:20 & Ledbetter et al. (12) & Becton Dickinson \\
\hline
\end{tabular}

* Becton Dickinson, Oxnard, CA.

$\uparrow$ Seralab, Sussex, UK.

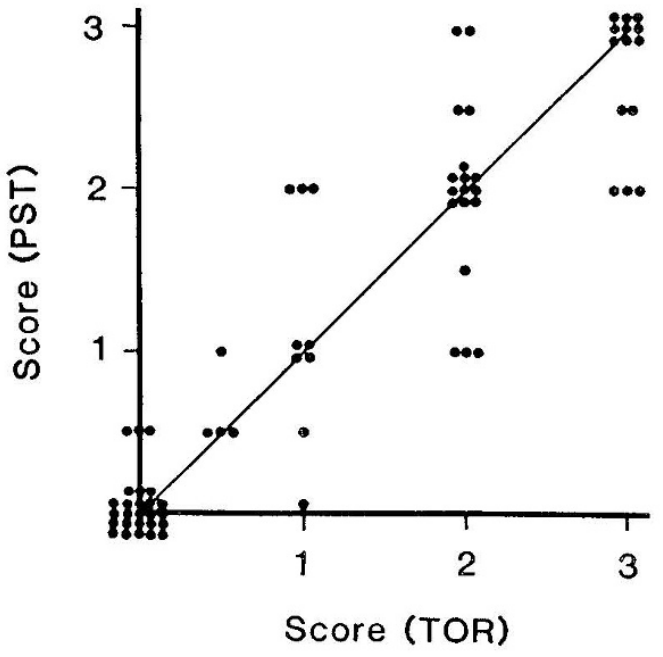

Fig. 1. Blind interobserver reproducibility of the immunofluorescence scoring system for intensity of the epithelial staining. Forty-nine out of 72 scores were identical and discrepant scores were symmetrically distributed around the identity line.

duodenal mucosa during the postmortem examination and were paraffin embedded after fixation in cold ethanol either directly or after extraction in cold PBS for $24 \mathrm{~h} \mathrm{(5).}$

Immunohistochemistry. Adjacent tissue sections cut at $6 \mu \mathrm{m}$ were examined by direct two-color immunofluorescence staining for duodenal epithelial SC, and IgA-, IgM-, IgG-, and IgDproducing cells in the lamina propria $(6,7)$. Murine MAb to HLA class I and class II (DR, DP, and DQ) and CD3+ (Table 2) were combined with a rabbit antiserum to keratin (for delineation of epithelium) (13) in a three-step avidin/biotin-enhanced two-color immunofluorescence method (14).

Fluorescene microscopy. Observations were performed in either a Leitz Orthoplan or a Leitz Aristoplan fluorescence microscope (Leica Microscopie and Systeme GmbH, Wetzlar, Germany). Narrow-band excitation and selective filtration of green and red fluorescence colors were obtained with a Ploemtype epi-illuminator.

The density of IgA-, IgM-, and IgG-producing cells were determined by means of an ocular grid and recorded as cell numbers per grid area $\left(0.02 \mathrm{~mm}^{2}\right)$. IgD-producing immunocytes and CD3 + T cells were only recorded as present or absent.

Staining for SC was scored semiquantitatively on a scale of 0 to 3 . A score of 0 was given for virtually no specific epithelial fluorescence, whereas a score of 3 indicated a normal staining pattern as seen in older children and adults. Epithelial HLA class I and class II expression was also scored from 0 (virtually no staining) to 3 (intense overall staining of the intestinal villi).

The interobserver reproducibility of the scoring system was tested blindly. There were 49 identical scores out of 72 observations, and discrepant scores were symmetrically distributed around the identity line (Fig. 1). In a previous study, interobserver reproducibility of cell counting was found to be satisfactory (15).

\section{RESULTS}

Variables of secretory immunity. Relatively small amounts of epithelial SC were present before the 29th gestational wk (Fig. $2 a$ ), but from then on it increased rapidly; 1 wk after birth, SC showed a normal distribution pattern like that in older children (Fig. 2b).

In the lamina propria, no IgA immunocytes were present until 2 wk after birth (Figs. $2 a$ and $b$ and 3). A few IgM and IgG immunocytes were present throughout the period investigated (Fig. 3).

In 10 cases from the entire period investigated, scattered B lymphocytes with membrane-bound IgD were seen, especially from the three cases with gestational age of $32 \mathrm{wk}$. In all cases T cells (CD3+) were observed, and they seemed to be most numerous in the period between the 32 nd gestational wk and the time including the 1st postnatal wk (data not shown).

HLA class $I$ and II determinants. Epithelial HLA class I expression was present throughout the period studied (Fig. 4). There were also class I-positive cells in the lamina propria. Epithelial class II (HLA-DR) determinants were virtually absent until $1 \mathrm{wk}$ after birth (Figs. $2 c$ and 4). Thereafter, most cases showed intense DR positivity on the duodenal villi (Fig. $2 d$ ). During the whole observation period, there were several DRpositive mononuclear cells in the lamina propria (Fig. $2 c$ and $d$ ).

Epithelial HLA-DP and -DQ were undetectable (Fig. 4), whereas DP- and DQ-positive mononuclear cells were seen in the lamina propria throughout the observation period.

\section{DISCUSSION}

The present paper demonstrates that the intestinal secretory immune system undergoes a rapid development during the first weeks after birth. HLA-DR is intensely expressed by the duodenal villous epithelium after the 1st postnatal wk and IgA immunocytes appear in the lamina propria after the $2 \mathrm{nd} \mathrm{wk}$.

Our study agrees with previous observations suggesting that IgA-producing cells are not normally present in the human gut (including the appendix) before $10 \mathrm{~d}$ of age (16-18). We found that a few IgG- and IgM-producing cells were present during fetal life. For the latter class, a significant increase was seen after birth, and the percentage of IgM cells is higher early in infancy than later on in childhood, as was also reported by others (17, 18). Ogra et al. (19) were unable to demonstrate Ig-producing cells in fetal life. However, they studied fetuses with gestational age below $22 \mathrm{wk}$, and they regularly observed $\mathrm{IgG}$ in the interstitial area of the small bowel, which of course might have been of maternal origin. Blanco et al. (20) observed no significant increase in intestinal immunocytes after $1 \mathrm{y}$, although IgM immunocytes decreased. A similar trend has been reported by others, but with increasing IgA immunocytes (21) even after 2 y (22). However, there may be striking geographical variation in postnatal development of intestinal IgA depending on the microbial exposure of the newborn.

The expression of SC by intestinal epithelium in fetal life agrees with the report of Ogra et al. (19). Because IgA-producing cells were absent until the 2 nd postnatal wk, it is clear that SC synthesis is independent of the B cell system, as is also seen in 

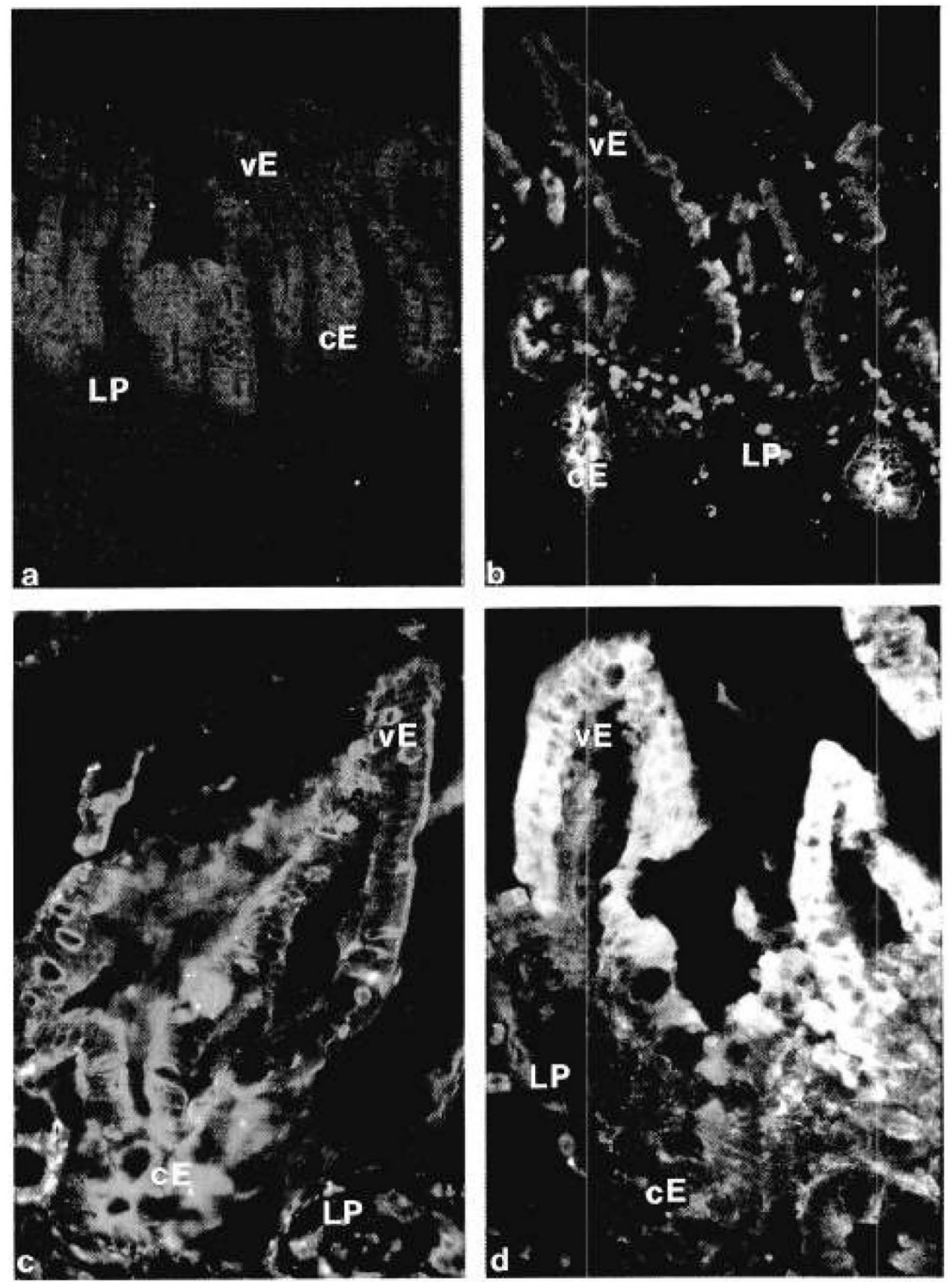

Fig. 2. Upper panels show duodenal mucosa of a fetus (a) (24th gestational wk) and of an infant $(b)(12 \mathrm{wk}$ old) stained green for SC and red for IgA (double exposures). In $a$, both crypt epithelium $(c E)$ and the basal part of villous epithelium $(v E)$ are positive for SC, but there are no IgA immunocytes in lamina propria $(L P)$. In $b$, both crypt epithelium and basal part of villous epithleium show yellow fluorescence, indicating colocalization of SC and IgA. In addition, there are numerous IgA immunocytes (red) in the lamina propria. Lower panels show duodenal mucosa of a fetus $(c)$ (32nd gestational wk) and of a full-term infant $(d)(1 \mathrm{wk}$ old) stained green for HLA-DR and red for keratin (double exposures). In $c$, the keratin-positive epithelium of the villi $(\nu E)$ and the crypts $(c E)$ is negative for HLA-DR, whereas there are several DR-positive mononuclear cells and endothelial cells in the laminia propria. In $d$, the keratin-positive villous epithelium is also intensely positive for HLA-DR (yellow coexpression), whereas the crypt epithelium is virtually DR-negative. In the lamina propria, there are numerous DR-positive mononuclear cells.

immunodeficient patients. However, the intensified SC expression seen especially shortly after birth might reflect activation of the mucosal immune system, because both interferon- $\gamma($ IFN- $\gamma$ ) and tumor necrosis factor- $\alpha$ are able to up-regulate $\mathrm{SC}(23,24)$.

The finding of HLA-DR on villous epithelium from the 1st wk of postnatal life probably reflects that this expression also depends on environmental stimulation. Our observation fits with those of Natali et al. (25) in humans and Mayrhofer et al. (26) in rats, whereas faint and inconsistent positivity on the tips of the villi has been reported for human fetuses by others $(27,28)$.
In the two latter studies, epithelial DR expression was seen after a gestational age of $18 \mathrm{wk}$, when prostaglandins are often applied for termination of pregnancies; it remains obscure whether this mediator might have influenced the results.

If the villous epithelium in fact has some constitutive and developmentally dependent class II expression, its striking upregulation shortly after birth might be explained by several cytokines, such as interferon- $\tau$ and TNF- $\alpha$, released by activated $\mathrm{T}$ cells and macrophages $(24,29)$ in harmony with the postnatal development of the secretory immunity. 


\section{Score for epithelial staining intensity}

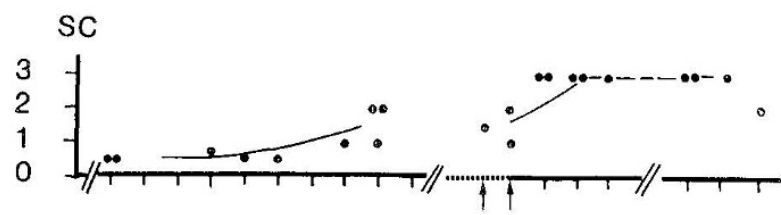

Cells per mucosal tissue unit IgA

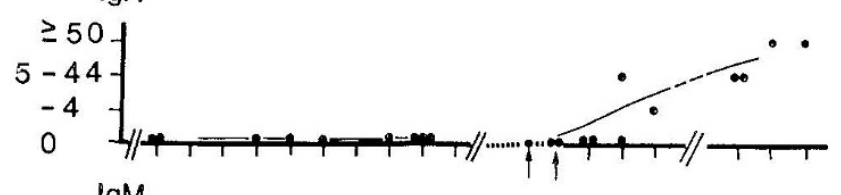

$\lg M$

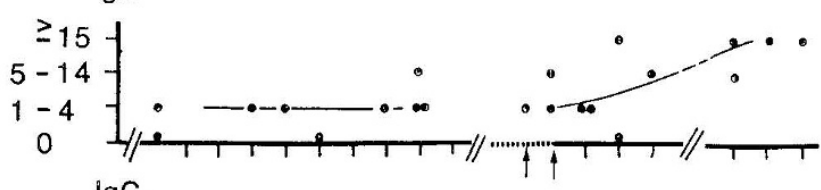

IgG

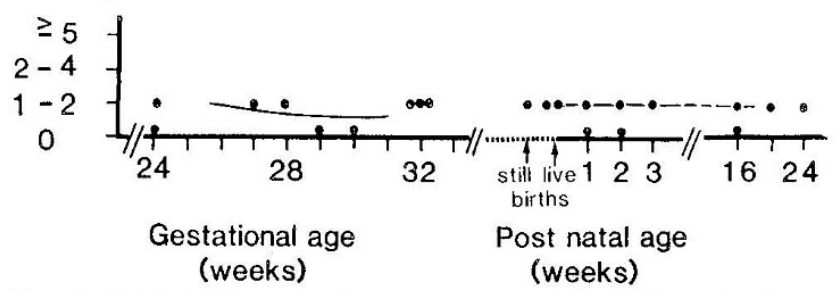

Fig. 3. Epithelial immunofluorescence scores for SC, and cell numbers per grid unit for IgA, IgM, and $\operatorname{IgG}$ in relation to gestational age and postnatal age. Still births and live births are indicated by separate arrows. Epithelial SC is present in normal amounts $1 \mathrm{wk}$ after birth and IgA immunocytes appear after the 2 nd postnatal wk. IgM and IgG cells are present throughout the time studied, but IgM immunocytes seem to increase in number after the 2 nd postnatal wk.

\section{Score for epithelial staining intensity}

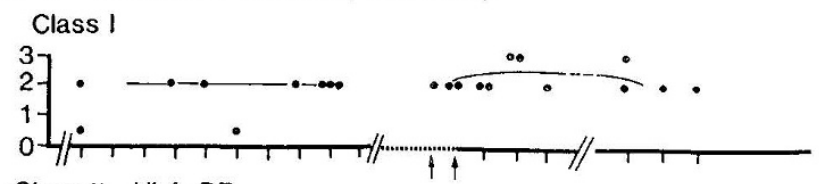

Class II HLA-DR

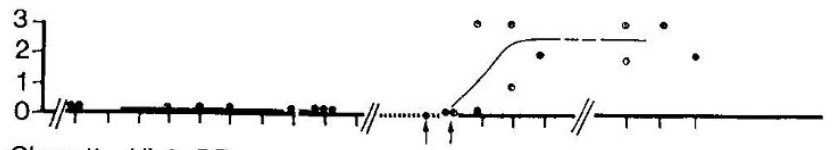

Class II HLA-DP

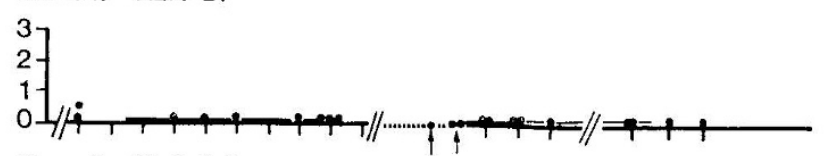

Class II HLA-DQ

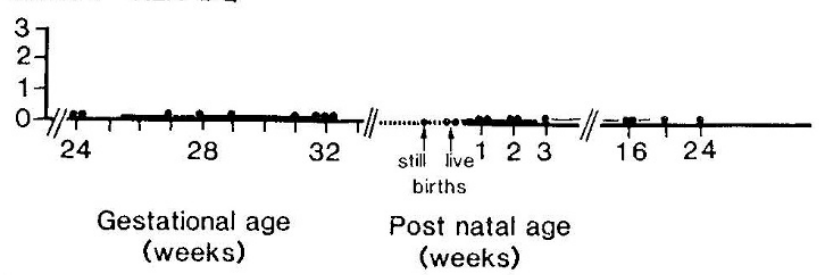

Fig. 4. Epithelial immunofluorescnece scores for HLA class I and class II (DR, DP, and DQ) determinants in relation to gestational age and postnatal age. Epithelial class I determinants are unchanged throughout the period studied. Epithelial HLA-DR determinants are absent in fetal life, but appear on the villi from the 1st postnatal wk. Epithelial HLA-DP and -DQ determinants are absent throughout the period studicd.
In conclusion, epithelial HLA-DR determinants and mucosal IgA immunocytes seem to appear in the human gut 1 to $2 \mathrm{wk}$ after birth, apparently reflecting a response to environmental factors. Knowledge about the development of the normal intestinal immune system is necessary for the understanding of pathologic conditions.

Acknowledgments. The authors thank Hanne Malmstrøm, Gunn Jamne, and Anne Gunn Winge for technical assistance.

\section{REFERENCES}

1. Brandtzaeg P, Halstensen TS, Kett K, Krajici P, Kvale D, Rognum TO, Scot H, Sollid LM 1989 Immunology and immunopathology of human gut mucosa: humoral immunity and intraepithelial lymphocytes. Gastroenterology 97:1562-1584

2. Ogra PL, Ogra SS, Coppola PR 1975 Secretory component in sudden infant death syndrome. Lancet 28:387-390

3. Hong R 1987 Immunity, allergy, and related diseases: the immunologic system. In: Behrman RE, Vaughan VC (eds) Nelson Textbook of Pediatrics. WB Saunders, London, p 464

4. Bach FH 1985 The HLA class II genes and products: the HLA-D region. Immunol Today 6:89-94

5. Brandtzaeg P 1974 Mucosal and glandular distribution of immunoglobulin components. Immunohistochemistry with a cold ethanol-fixation technique. Immunology 26:731-737

6. Brandtzaeg P, Baklien K, Fausa O, Hoel PS 1974 Immunohistochemical characterization of local immunoglobulin formation in ulcerative colitis. Gastroenterology 66:1123-1136

7. Rognum TO, Brandtzaeg P, Ørjasaeter H, Elgjo K, Hognestad J 1980 Immunohistochemical study of secretory component, secretory IgA, and carcinoembryonic antigen in large bowel carcinomas. Pathol Res Pract 170:126145

8. Lampson LA, Levy R 1980 Two populations of Ia-like molecules on human B cell line. J Immunol 125:293-299

9. Chen YX, Evans RL, Pollack MS, Lanier LL, Phillips JH, Rousso C, Warner NL, Brodsky FM 1984 Characterization and expression of the HLA-DC antigens defined by anti-Leu 10. Human Immunol 10:221-235

10. Watson AJ, DeMars R, Throwbridge IS, Bach FH 1983 Detection of a novel human class II HLA antigen. Nature 304:358-361

11. Barnstable CC, Bodmer WF, Brown G, Galfre G, Milstein C, Williams A-F, Ziegler A 1978 Production of monoclonal antibodies to group A erythrocytes, HLA and other human cell surface antigens: new tools for genetic analysis. Cell 14:9-20

12. Ledbetter JA, Evans RE, Lipinski M, Cunningham-Rundles C, Good RA, Herzenberg LA 1981 Evolutionary conservation of surface molecules that distinguish $\mathrm{T}$ lymphocytes helper/inducer and $\mathrm{T}$ cytotoxic/suppressor subpopulations in mouse and man. J Exp Med 153:310-323

13. Huitfeldt HS, Brandtzaeg P 1985 Various keratin antibodies produce immunohistochemical staining of human myocaridum and myometrium. Histochemistry 83:381-389

14. Brandtzaeg P, Rognum TO 1983 Evaluation of tissue preparation methods and paired immunofluorescence staining for immunocytochemistry of lymphomas. Histochem J 15:655-689

15. Stoltenberg L, Saugstad OD, Rognum TO 1992 SIDS victims show local IgM response in tracheal wall and IgA response in duodenal mucosa. Pediatr Res 31:372-375

16. Perkkio M, Svailahti E 1980 Time of appearance of immunoglobulin-containing cells in the mucosa of the neonatal intestine. Pediatr Res 14:953-955

17. Knox DF 1986 Restricted feeding and human intestinal plasma cell development. Arch Dis Child 61:744-749

18. Gebbers J-O, Laissue JA 1990 Postnatal immunomorphology of the gut. In: Hadziselimovic F, Herzog B, Bürgin-Wolff A (eds) Inflammatory Bowel Disease and Coeliac Disease in Children. Kluwer, Dordrecht, The Netherlands, pp 3-44

19. Ogra SS, Ogra PL, Lippes J, Thomasi TB 1972 Immunohistological localization of immunoglobulins, secretory component, and lactoferrin in developing human fetus. Proc Soc Exp Biol Med 139:570-574

20. Blanco A, Linares P, Andion R, Alonso M, Sanchez-Villares E 1976 Development of humoral immunity system of the small bowel. Allergol Immunopathol (Madr) 4:235-240

21. Savilahti E 1972 Immunoglobulin-containing cells in the intestinal mucosa and immunoglobulins in the intestinal juice in children. Clin Exp Immuno $11: 415-425$

22. Maffei HVL, Kingston D, Hill ID, Shiner M 1979 Histopathologic changes and the immune response within the jejunal mucosa in infants and children. Pediatr Res 13:733-736

23. Kvale D, Løvhaug D, Sollid LM, Brandtzaeg P 1988 Tumor necrosis factoralpha upregulates expression of secretory component, the epithelial receptor for polymeric Ig. J Immunol 140:3086-3089

24. Sollid LM, Kvale D, Brandtzaeg P, Markussen P, Thorby E 1987 Interferon- $\tau$ enhances expression of secretory component, the epithelial receptor for polymeric immunoglobulins. J Immunol 138:4303-4306

25. Natali PG, Russo C, Ng AK, Nicotra MR, Apollonj C, Pellegrino MA, Ferrone S 1982 Ontogeny of human Ia antigens. Cell Immunol 73:385-396

26. Mayrhofer G, Pugh CW, Barclay AN 1983 The distribution, ontogenity and 
origin in the rat of la-positive cells with dendritic morphology and of Ia antigen in epithelia, with special reference to the intestine. Eur $\mathrm{J}$ Immunol 13:112-122

27. MacDonald TT, Weinel A, Spencer J 1988 HLA-DR expression in fetal intestinal epithelium. Gut 29:1342-1348

28. Oliver AM, Thomson AW, Sewell HF, Abramovich DR 1988 Major histocompatibility complex (MHC) class II antigen (HLA-DR, DQ, and DP) expres- sion in human fetal endocrine organs and gut. Scand J Immunol 27:731737

29. Kvale D, Brandtzaeg P, Løvhaug D 1988 Up-regulation of the expression of secretory component and HLA molecules in a human colonic cell line by tumour necrosis factor- $\alpha$ and gamma interferon. Scand J Immunol 28:351357

\section{Announcement}

\section{World Congress on Rett Syndrome}

The World Congress on Rett Syndrome will be held October 7-10, 1993 in Antwerp, Belgium. Parents, physicians, psychologists, therapists, and teachers are invited to participate in the congress. For further information, contact Vanherck Peter, Lil 26, B-2450 Meerhout, Belgium, Fax: 32014303157. 